\title{
Radial Nerve Mobilization Reduces Lateral Elbow Pain and Provides Short-Term Relief in Computer Users ${ }^{\S}$
}

\author{
Vanitha Arumugam ${ }^{*}, 1$, Senthil Selvam² ${ }^{2}$ and Joy C. MacDermid ${ }^{3}$ \\ ${ }^{I}$ University of Western Ontario, Health and Rehabilitation Sciences, Faculty of Health Sciences, London, Ontario, \\ Canada \\ ${ }^{2}$ Vel's School of Physiotherapy, Vel's University, Chennai, India \\ ${ }^{3}$ McMaster University, School of Rehabilitation Science, Hamilton, Ontario, Canada; Clinical Research, Roth McFarlane \\ Hand and Upper Limb Center, St. Joseph's Hospital, London, Ontario, Canada
}

\begin{abstract}
Study Design: Prospective Experimental Study.
Background: Computer users may be at risk of lateral elbow pain. It is theorized that adverse mechanical tension can arise in the radial nerve with sustained keyboarding due to sustained static work of the elbow extensor muscles. Neural mobilization has been suggested as a potential treatment.

Purpose: The purpose of this study was to evaluate the effect of neural mobilization of the radial nerve on a single occasion in terms of its ability to reduce lateral elbow pain.

Methods and Analysis: Forty-one computer professionals (Mean age 46.7; S.D. 12.77), who had experienced lateral elbow pain for a mean of 2.87 months were recruited. The participants rated the pain using a verbal, numeric rating scale (NRS). Radial nerve tension was tested using the Upper limb Tension Test (ULTT) for radial nerve in both upper extremities. The radial nerve was mobilized using a series of 8 oscillations and repeated 3 times with a one minute rest in between. The NRS and ULLT were repeated after treatment and the scores compared using a paired t-test by the first author.
\end{abstract}

Results: The mean NRS scores decreased significantly from $5.7(1.1)$ to $3.8(1.4)(\mathrm{p}<0.000 ; \mathrm{t}$ value=8.07).

Conclusion: A single session of 3 neural mobilization resulted in a reduction of pain in computer users with lateral elbow pain. A long-term randomized trial is needed to determine the effects sustained over-time.

Keywords: Butler's technique of neural mobilization, lateral elbow pain, neural tension testing, numerical rating scale.

\section{INTRODUCTION}

Extensive computer use is common for many individuals either for occupational, social or recreational tasks. Thus, the cumulative amount of time spent on a keyboard may be substantial for many individuals resulting in an increase in concerns for upper extremity disorders related to "overuse". The involvement of the peripheral nervous system in "nonspecific" upper limb pain and dysfunction in computer operators has been suggested in previous reports and studies [1-8].

Numerous impairments such as increased threshold to vibratory stimulation, tension in the nerves, reduced nervous mobility, mechanical allodynia, pathological change in axonal flare reaction, and reduction in muscle strength have

*Address correspondence to this author at the DB-222 Roth McFarlane Hand and Upper Limb Center, St Joseph's Healthcare London, London, ON N6A 4L6, Canada;

Tel: +1-519-646-6100, Ext. 64636; Fax: +1-519-646-6049;

E-mails: varumuga@uwo.ca, vanithaphysio@gmail.com

${ }^{\S}$ This study was approved by the Health Sciences Research Ethics Board (HSREB) of the Tamil Nadu Dr. MGR Medical University, Chennai, India. been reported in computer users who have experienced pain. These impairments can be related to involvement of the peripheral nervous system [9]. A study among 485 injured workers of which $70 \%$ were computer users, found that although upper extremity disorders typically present with distal symptoms in the beginning; the disorder is actually a combination of diffuse neuromuscular illness with the proximal upper-body impairments that affect distal function. The authors supported the concept that posture related neurogenic compression is a key factor in work-related upper extremity disorder [5].

Lateral elbow pain is one of the most common musculoskeletal problems reported by computer professionals and has been attributed to several causes [1015]. For example, in a detailed examination of injured workers who were predominantly computer users, $7 \%$ of patients were identified as having radial tunnel and $33 \%$ were identified as having lateral epicondylosis [9]. The patho-anatomic mechanisms behind symptoms of lateral elbow pain are unknown, but local vascular abnormalities [16], thermographic changes [17], and minor nerve entrapment [18-20] have been investigated. Nerves move in relation to their surrounding connective tissues $[21,22]$. Entrapment of a nerve can restrict nerve movement 
and can cause ischemia, pain, inflammation, axonal degeneration, vascular compromise, leading abnormal tension in the nerve called "adverse mechanical tension" [2325]. Injured or inflamed peripheral nerves usually have increased sensitivity to mechanical loading [26].

Peripheral nerves are susceptible to mechanical compression, friction, and repeated tension [27]. If sufficient mechanical stimuli are exerted upon the nerve to cause damage; the damaged cells will release number of chemical agents, including bradykinin, histamine and prostaglandins. These chemical agents are capable of directly stimulating the nociceptors found within the connective tissue layers of the nerve [28]. Compression can also result in structural damage, blockage of axoplasmic flow, and impairment of blood flow resulting in ischemia, all of which will result in altered function of the nerve [29-33]. In addition, chemicals released from non-neural tissues are capable of mediating an inflammatory response, stimulating nociceptors within the connective tissue of nerves [30]. Lateral elbow pain in some cases is related to compression of the radial nerve at the radial tunnel $[34,35]$. Nerve tension testing, which causes mechanical tension on a nerve is expected to increase pain from the nerve [36]. There is support for this concept immediately following neural tension, positioning in people without any pathology there is an increase in the threshold of sensory reception touch; and decreased threshold for pain [37]. David Butler described nerve tension testing positions and mobilization techniques for the nerves of the upper extremity [38].

Techniques that restore the mobility of a nerve that has restricted longitudinal movement are often called "neural mobilization techniques" $[24,25]$. When neural mobilization is used for treatment of adverse neural tension, the primary theoretical objective is to restore the dynamic balance between the relative movement of neural tissues and surrounding tissue interfaces. This will in turn reduce intrinsic pressure on neural tissues and promote optimum physiologic function [39]. Based on this premise for this intervention one might expect improved mobility of the nerve and visceral structures following neural mobilization. Hence, the purpose of this study is to analyze the short-term effect of radial nerve mobilization in reducing lateral elbow pain.

\section{MATERIALS AND METHODOLOGY}

\section{Study Design: Prospective (Pre-Post) Study}

Selection and Description of Participants: Participants were recruited by one of the authors from various multinational companies in Chennai, India. The eligibility criteria for this study was: subjects must present with a new episode of lateral elbow pain; were working on computers for a period of 6 to 8 hours per day; were experiencing lateral elbow pain and radiating pain of 2 to 6 months duration; were aged between 18 and 60 years. The exclusion criteria was, if any of the screening tests of shoulder abduction and hand behind back showed a lack of movement or pathology that could limit the mechanical application of the neural tissue tension test; predominant systemic illness; neurological disturbance or psychiatric; or history of a traumatic fracture of the spine which resulted in permanent neurological deficit. People who underwent spinal or upper limb surgery were also excluded.

\section{Demographics}

The study included 20 males and 21 females $(n=41) .35$ individuals were right hand dominant and 6 were left hand dominant. Recruited participants provided an informed consent form as approved by the research Ethics Board of the Tamil Nadu Dr. MGR Medical University, Chennai, India.

\section{Outcome Measure}

Pain was measured using Numeric Rating Scale for pain (NRS-P). The NRS-P is a $10 \mathrm{~cm}$ long line calibrated from 0 to 10 where no pain is recorded as 0 and severe pain as 10 . The NRS has been shown to have 0.64 to 0.86 , good to excellent test-retest reliability [40].

\section{Procedure}

All participants were informed of the protocol before participating in the study. Pain was measured using NRS-P and then the mobilization was completed.

\section{Mobilization}

The participants were positioned in a supine lying position. The physiotherapist assumed a standing position. The shoulder girdle was depressed, elbow extended, arm internally rotated, wrist, thumb and fingers were flexed. These movements stressed the radial nerve, and then shoulder depression was maintained with elbow flexion and wrist extension $[25,27,41]$. The wrist and fingers were fixed prior to the elbow extension test that was performed gently, extending the elbow for approximately 2 seconds just into the range where the participant felt only the tension but no pain and then flexing the elbow. Three sets of 6 to 8 oscillations were performed. NRS-P was re-assessed to ascertain change. Measurements were performed by a single physiotherapist.

\section{Statistical Analysis}

Statistical analysis was performed using the SPSS software. A paired test of significance was performed to find out the difference in pre and post-test means of pain scores. The level of statistical significance was set at $\mathrm{p}<0.05$.

\section{RESULTS}

There was an immediate reduction in the pain reported by the participants post-intervention. The mean NRS scores decreased significantly after the intervention from 5.7 (1.1) to $3.8(1.4)(\mathrm{p}<0.000 ; \mathrm{t}$ value $=8.07)$.

\section{DISCUSSION}

This study found immediate reduction in lateral elbow pain after radial nerve mobilization in computer users. This provides preliminary support for the usage of neural mobilization techniques in the treatment of lateral elbow pain.

Participants did not have severe upper extremity problems upon enrollment in the study since they were currently working. However, they did have signs and symptoms that we attributed to neurogenic impairment 
because of the distribution and behavior of pain and the response to neural tissue provocation tests. Mechanical reproduction of symptoms that are detected by changing tension in neural tissues while not influencing the non-neural structures was used as a strategy to identify the symptoms. However, work-related upper extremity disorders have been shown to be multifactorial. It can be difficult to distinguish neurogenic symptoms from other potential physical and psychological contributors to their symptoms, which are out of the scope of this study.

The upper limb tension tests have moderate to substantial reliability [41]. Yaxley and Jull found that the neural tension test with a bias towards the radial nerve reproduced symptoms in $55 \%$ of lateral elbow pain cases [40]. This supports the use of radial nerve mobilization with patients complaining of lateral elbow pain. This study indicates that the mobilization of the radial nerve alters pain threshold in the periphery and these effects reduce pain in the short-term in patients with lateral elbow pain. This is because, as neural tension decreases, pain is decreased related to movement or bodily position restoring normal movement.

While this study provides initial support for short-term impacts of radial nerve mobilization for computer users with neurogenic type lateral elbow pain, but our findings were tempered due to our study limitations. The most substantial limitation is that the evaluation, treatment and assessment of outcome were not separated but rather provided by a single therapist. As such the measurement of motion was subject to provider bias. This effect was countered to some extent by the use of the patient reported numeric pain rating scale. While this measure was provided by patients and was verbally reported to the therapist, therefore, there is potential for social desirability bias. No physical performance tests were performed to indicate whether short-term changes in motion and pain were associated with increased function. Finally, since we only evaluated the impact of a single session, this provides no evidence about the long-term effects of this treatment. Long-term studies are required to see whether such an approach would reduce the incidence of upper extremity disorders, particularly at the radial tunnel. Since work related lateral elbow pain is multifactorial, a measure of multiple outcomes and evaluation of the effectiveness of an overall program and their individual components should be used.

\section{CONCLUSION}

The results of the study indicate that the mobilization of the radial nerve resulted in a significant short-term relief in the lateral elbow pain of computer users.

\section{CONFLICT OF INTEREST}

The authors confirm that this article content has no conflict of interest.

\section{ACKNOWLEDGEMENTS}

Declared none.

\section{REFERENCES}

[1] Brandt LP, Andersen JH, Lassen CF, et al. Neck and shoulder symptoms and disorders among danish computer workers. Scand J Work Environ Health 2004; 30(5): 399-409.
[2] Gerr F, Marcus M, Monteilh C. Epidemiology of musculoskeletal disorders among computer users: Lesson learned from the role of posture and keyboard use. J Electromyogr Kinesiol 2004; 14(1): 25-31.

[3] Haufler AJ, Feuerstein M, Huang GD. Job stress, upper extremity pain and functional limitations in symptomatic computer users. Am $\mathrm{J}$ Ind Med 2000; 38: 507-15.

[4] Keller K, Corbett J, Nichols D. Repetitive strain injury in computer keyboard users: Pathomechanics and treatment principles in individual and group intervention. J Hand Ther 1998; 11(1): 9-26.

[5] Pascarelli EF, Hsu YP. Understanding work-related upper extremity disorders: Clinical findings in 485 computer users, musicians, and others. J Occup Rehabil 2001; 11(1): 1-21.

[6] Waugh EJ, Jaglal SB, Davis AM. Computer use associated with poor long-term prognosis of conservatively managed lateral epicondylalgia. J Orthop Sports Phys Ther 2004; 34(12): 770-80.

[7] Jepsen J. Upper limb neuropathy in computer operators? A clinical case study of 21 patients. BMC Musculoskeletal Disorders 2004; 5(1): 26 .

[8] Potter HG, Hannafin JA, Morwessel RM, DiCarlo EF, O'Brien SJ, Altchek DW. Lateral epicondylitis: Correlation of MR imaging, surgical, and histopathologic findings. Radiology 1995; 196(1): 436.

[9] Coonrad RW, Hooper WR. Tennis elbow: Its course, natural history, conservative and surgical management. J Bone Joint Surg Am 1973; 55(6): 1177-82.

[10] Chard MD, Cawston TE, Riley GP, Gresham GA, Hazleman BL. Rotator cuff degeneration and lateral epicondylitis: A comparative histological study. Ann Rheum Dis 1994; 53(1): 30-4.

[11] Johnston J, Plancher KD, Hawkins RJ. Elbow injuries to the throwing athlete. Clin Sports Med 1996; 15(2): 307-29.

[12] Gunn CC, Milbrandt WE. Tennis elbow and the cervicla spine. Can Med Assoc J 1976; 114(9): 803-9.

[13] Ebbetts J. Autonomic pain in the upper limb. Physiotherapy. 1971; 57(6): 270-9.

[14] Pritchard MH, Pugh N, Wright I, Brownlee M. A vascular basis for repetitive strain injury. Rheumatology (Oxford) 1999; 38(7): 636-9.

[15] Sharma SD, Smith EM, Hazleman BL, Jenner JR. Thermographic changes in keyboard operators with chronic forearm pain. BMJ 1997; 314(7074): 118.

[16] Greening J, Smart S, Leary R, Hall-Craggs M, O'Higgins P, Lynn B. Reduced movement of median nerve in carpal tunnel during wrist flexion in patients with non-specific arm pain. Lancet 1999; 354(9174): 217-8.

[17] Kryger AI, Andersen JH, Lassen CF, et al. Does computer use pose an occupational hazard for forearm pain; from the NUDATA study. Occup Environ Med 2003; 60(11): e14.

[18] Jensen BR, Pilegaard M, Momsen A. Vibrotactile sense and mechanical functional state of the arm and hand among computer users compared with a control group. Int Arch Occup Environ Health 2002; 75(5): 332-40.

[19] McLellan DL SM. Longitudinal sliding of the median nerve during movements of the upper limb. J Neurol Neurosurg Psychiat 1976; 39(6): 566-70.

[20] Wilgis EF, Murphy R. The significance of longitudinal excursion in peripheral nerves. Hand Clin 1986; 2(4): 761-6.

[21] Butler D, Gifford L. The concept of adverse mechanical tension in the nervous system part 1: Testing for 'dural tension. Physiotherapy 19890; 75(11): 622-9.

[22] Elvey RL. Treatment of arm pain associated with abnormal brachial plexus tension. Aus J Physiother 1986(32): 225-50.

[23] Butler DS, Ed. Mobilisation of the nervous system. New York: Churchill Livingstone Inc 1991.

[24] Schmid AB, Brunner F, Luomajoki H, et al. Reliability of clinical tests to evaluate nerve function and mechanosensitivity of the upper limb peripheral nervous system. BMC Musculoskelet Disord 2009; 10: 11,2474-10-11.

[25] Butler DS. Advance mechanical tension in the nervous system : A model for assessment and treatment. Aus J Physiother 1989; 36(4): 227-38.

[26] Nee RJ, Butler D. Management of peripheral neuropathic pain : Integrating neurobiology, neurodynamics and clinical evidence. Phys Ther Sport 2006; 6: 36-49.

[27] Dahlin LB, Sjostrand J, McLean WG. Graded inhibition of retrograde axonal transport by compression of rabbit vagus nerve. $\mathrm{J}$ Neurol Sci 1986; 76(2-3): 221-30. 
[28] Olmarker K, Rydevik B, Holm S. Edema formation in spinal nerve roots induced by experimental, graded compression. an experimental study on the pig cauda equina with special reference to differences in effects between rapid and slow onset of compression. Spine (Phila Pa 1976)1989; 14(6): 569-73.

[29] Powell HC, Myers RR. Pathology of experimental nerve compression. Lab Invest 1986; 55(1): 91-100.

[30] Rydevik B, Lundborg G, Bagge U. Effects of graded compression on intraneural blood blow. an in vivo study on rabbit tibial nerve. J Hand Surg Am 1981; 6(1): 3-12.

[31] Rydevik B, Brown MD, Lundborg G. Pathoanatomy and pathophysiology of nerve root compression. Spine (Phila Pa 1976) 1984; 9(1): 7-15.

[32] Lutz FR. Radial tunnel syndrome: An etiology of chronic lateral elbow pain. J Orthop Sports Phys Ther 1991; 14(1): 14-7.

[33] Verhaar J, Spaans F. Radial tunnel syndrome. an investigation of compression neuropathy as a possible cause. J Bone Joint Surg 1991; 73(4): 539-44.

[34] Ekstrom RA, Holden K. Examination of and intervention for a patient with chronic lateral elbow pain with signs of nerve entrapment. Phys Ther 200; 82(11): 1077-86.
[35] Costantini M, Tunks K, Wyatt C, Zettel H, MacDermid JC. Age and upper limb tension testing affects current perception thresholds. J Hand Ther 2006; 19(3): 307,16; quiz 317.

[36] Butler DS. The sensitive nervous system. Australia: Niogroup Publications 2000

[37] Ellis RF, Hing WA. Neural mobilization: A systematic review of randomized controlled trials with an analysis of therapeutic efficacy. J Man Manip Ther 2008; 16(1): 8-22.

[38] Stratford P, Spadoni G. The reliability, consistency and clinical application of a numeric pain rating scale. Physiother Canada 2001; 53(2): 88-91.

[39] Shacklock M. Clinical neurodynamics: A new system of musculoskeletal treatment. Adelaide, Australia: ButterworthHeinnemann 2005

[40] Yaxley GA, Jull GA. Adverse tension in the neural system. A preliminary study of tennis elbow. Aus J Physiother 1993; 39(1): $15-22$.

[41] Schmid A, Brunner F, Luomajoki H, et al. Reliability of clinical tests to evaluate nerve function and mechanosensitivity of the upper limb peripheral nervous system. BMC Musculoskeletal Disorders. 2009; 10(1): 1-9.

(C) Arumugam et al.; Licensee Bentham Open.

This is an open access article licensed under the terms of the Creative Commons Attribution Non-Commercial License (http://creativecommons.org/licenses/by-nc/3.0/) which permits unrestricted, non-commercial use, distribution and reproduction in any medium, provided the work is properly cited. 